\title{
Concept-guided development of technology in 'traditional' and 'innovative' schools: quantitative and qualitative differences in technology integration
}

\author{
Sandra de $\operatorname{Koster}^{1}$ (D) Monique Volman $^{1} \cdot$ Els Kuiper $^{1}$
}

Published online: 21 April 2017

(C) The Author(s) 2017. This article is an open access publication

\begin{abstract}
The integration of technology into the classroom remains a challenge for those involved. A concept-guided approach to the development of technology has been suggested as a way of meeting this challenge. This multiple case study was performed in the context of a project in which five elementary schools in The Netherlands with a school concept that was labeled as either 'traditional' or 'innovative' developed and realized up to four technology-supported learning arrangements in line with their schools' educational concepts. Through embedded case studies, including analysis of the learning arrangements and focus group interviews with the teachers involved, we found that in general the developed technology use became integrated in the teachers' classroom practices at all schools to a similar extent. Some differences were found between the schools, but hardly any were found between the school types. Both practical and theoretical implications of these findings are discussed.
\end{abstract}

Keywords Primary education · Technology integration · Concept-guided development $\cdot$ Teacher perspective

\section{Introduction}

An increasing body of studies indicates that digital technology has the potential to improve learning processes (cf. Archer et al. 2014; Cheung and Slavin 2012, 2013; Lemke et al. 2009). Well integrated use of technology in classroom practice is therefore by many considered desirable and is being advocated by many national governments (cf. Lewin and McNicol 2015). In the literature a considerable amount of attention is paid to factors that either impede or promote adoption and integration of technology. The fit between the

Sandra de Koster

sandradekoster@yahoo.com

1 University of Amsterdam, Nieuwe Achtergracht 127, Amsterdam, The Netherlands 
proposed technology use and the school's educational concept is considered to be one of the factors that promote the integration of technology (Zhao et al. 2002; Niederhauser and Stoddart 2001). Concept-guided development of technology, in which school teams develop and implement forms of technology use in line with the school's educational concept, is a pedagogy-driven approach that aims to promote this fit and is therefore expected to promote the integration of technology that can enhance learning. Previous studies (de Koster et al. 2012, 2013) have shown that schools with different educational concepts, either 'traditional' or 'innovative', ' that developed their use of technology in a concept-guided way, realized clearly distinguishable types of technology use, aimed at supporting various types of teaching and learning. It was not known, however, whether this would lead to similar levels of integration in schools with different educational concepts. In this present study we investigated how the integration of the developed technology use into the different school types' classroom practices can be characterized in quantitative and qualitative terms.

\section{Background}

Over the past 25 years a body of literature has developed that focuses on finding promising approaches to the integration of technology in education. In this literature we find a shift from a strong focus on the technology and its opportunities for teaching and learning to a focus on pedagogical desirabilities and the ways in which certain technologies can support these (Ertmer and Ottenbreit-Leftwich 2013; Kampylis et al. 2013; Lewin and McNicol 2015; Mor and Mogilevsky 2013). This study clearly has the latter focus, being concerned with the integration of technology that has been identified by the teachers involved as providing a possible support for the teaching and learning that they aim for.

\section{Defining technology integration}

Before we discuss different ways of promoting the integration of technology into school practices we need to have a clear definition of what is technology integration. Reviews of the literature on technology integration indicate that there is no unequivocal interpretation of this term (e.g. Hew and Brush 2007; Vanderlinde 2011). An often used indicator for technology integration is the quantity of use, like the number of computers available to students or the frequency with which technology is used, generally associating higher frequencies of use with higher levels of integration (e.g. Mueller et al. 2008; Tondeur et al. 2008). Here caution is due, as a comprehensive comparative PISA study (OECD 2015) shows that although moderate frequencies of computer use at school can improve learning outcomes, very high frequencies of use appear to lead to considerably lower learning outcomes. Therefore a high frequency of technology use in itself is not what schools should strive for. On the other hand we find studies that focus instead on the pedagogies that are being supported with technology. Many of these studies imply that technology can only be considered 'integrated' when it supports a specific type of teaching and learning. One example is the still frequently cited five stage model of (Sandholtz et al. 1997), which suggests that the highest stage of technology integration is only found in a context of innovative, constructivist teaching and learning (Mueller et al. 2008). Likewise Lim (2007)

\footnotetext{
1 As the labeling of these school types as traditional and innovative is indicative rather than conclusive we use quotation marks when referring to the school types.
} 
characterizes effectively integrated technology use in terms of teachers using technology to develop students' thinking skills. In these studies the ultimate goal of integrating technology that is aimed for is a use of technology that supports one specific type of pedagogy. A more general definition that can be used-regardless of the school's pedagogy-is that integration of classroom technology means that it becomes an integral part of how the classroom functions, i.e. that is becomes as accessible as all other classroom tools (ISTE 2002), or that it becomes a 'natural' element in classroom practice (Vanderlinde and van Braak 2010).

\section{Promoting the integration of technology in educational practice}

From the literature a number of conditions that promote successful integration of technology, in terms of technology being used and regardless of how it is used pedagogically, become apparent. Many conditions have been identified at the level of the teacher-e.g. technological competency, readiness for ICT integration-, and of the school-e.g. ICT infrastructure, provision of time, training and support, and school-wide ICT integration planning) (Hew and Brush 2007; Inan and Lowther 2010; Pelgrum 2001; Van Braak et al. 2004; Ward and Parr 2010; Vanderlinde et al. 2009). A condition that is receiving growing attention is the fit between technology use and the educational concept of the school. (Zhao et al. 2002) describe this in terms of the distance between the technology innovation (i.e. the intended development of the school's use of technology) on the one hand, and the school's educational culture and practice on the other hand. The shorter this distance, the better chances are for successful technology integration. This is consistent with findings indicating that how and with what learning effects technology resources are used, depends on how well they fit in with the established patterns of activity in a school (Tolmie 2001). Similarly, Niederhauser and Stoddart (2001) found that teachers are inclined to apply technology in a manner that is consistent with their personal perspectives about curriculum and instructional practice. Other studies as well have found a fit with the school's pedagogy, often defined as the school's teaching strategies, techniques or approaches used to deliver instruction or facilitate learning (Wang 2008), to be essential in supporting the integration of technology into classroom practices (Mandell et al. 2002; Wang 2008). In order to encompass both the operational level of strategies and techniques and the underlying motivational level of perspectives and beliefs, we propose to label this factor as the school's educational concept.

\section{Concept-guided development of technology use}

From the findings discussed above, we conclude that if use of technology is developed to fit the school's educational concept (encompassing both the school's pedagogical practices and the beliefs and perspectives that motivate these practices), the chances of successful integration of technology are increased. Based on this conclusion a concept-guided approach to developing technology use, i.e. taking the school's educational concept as the main starting point for developing its use of technology, has been proposed as a way to help schools integrate technology into their teaching and learning.

A concept-guided approach to development of technology use calls for a definition that gives room to a variety of educational concepts. From this viewpoint the level of technology integration that can be achieved does not by definition depend on the school's educational concept (Sandholtz et al. 1997; Mueller et al. 2008; Lim 2007) but rather depends on how well the technology use fits into existing or desired classroom practices in 
a school. We propose therefore that this definition of technology integration should encompass the perceptions of the teachers who carry out these concepts in their everyday work. The question whether technology is successfully integrated should therefore include whether the teachers involved appreciate the way the technology fits into their classroom practices.

\section{This study}

This definition became the starting point for our study of the integration of technology use that was developed by five Dutch primary schools participating in a project that aimed at concept-guided development of technology use. This definition of integration-as-perceived-by-the-teacher was combined with a quantitative indicator of technology integration: the amount of technology that is available and accessible to students (ISTE 2002).

Two schools with a 'traditional' and three schools with an 'innovative' educational concept were selected to participate in this project, in order to explore the effects of this approach on the integration of technology in relation to different educational concepts. These labels referred only to the school concept, not to the level and type of technology use on entering the project. The labeling of the school types was based on three aspects that can be used to describe learning environments: learning goals (product versus process of learning), division of teacher and learner roles and roles of learners in relation to each other (de Kock et al. 2005). The label 'traditional' in this study refers to a fixed curriculum with a focus on learning products and transmission of knowledge and a strongly teacher-directed approach with limited room for input from students. The label 'innovative' indicates a more open curriculum with a focus on learning processes and knowledge construction and a student-centred approach. The school types are described in more detail in the next section. At each school a team of teachers was supported in designing and implementing up to four technology-supported learning arrangements of their own choosing. A previous study (de Koster et al. 2012) showed that the 'traditional' schools developed less complex use of technology that was more easily implemented, while the 'innovative' schools designed rather complex use of technology, which seemed to hinder its implementation. These findings suggest that concept-guided development of technology use might lead to concept-specific differences in the achieved levels of technology integration, possibly both in quantitative and in qualitative terms. In order to investigate whether this actually happened in this project we formulated the following main research question for this study:

How can the achieved integration of technology in 'traditional' and 'innovative' schools that develop their use of technology in a concept-guided way be characterized in quantitative and qualitative terms?

In order to answer this main question we formulated the following sub questions:

1. How can the achieved technology integration in these schools be characterized in quantitative terms, i.e. in terms of the number of available computers and the number of technology-rich learning arrangements that have been developed?

2. To what extent is the developed technology use perceived by the teachers as an integral part of their classroom practice?

3. What differences can be found between the school types with regard to these quantitative and qualitative indicators of technology integration? 


\section{Method}

\section{Context of this study}

The study was conducted in the context of a project of concept-guided development of technology use in the Netherlands in which five primary schools participated. During the project a team of teachers at each school designed, developed and realized up to four technology-enhanced learning arrangements over the course of two school years. A learning arrangement would consist of a lesson plan, including learning goals, tools and activities, and could concern any school subject. Learning arrangements could entail anything from the use of 'drill-and-practice' software to the use of a wide range of technological tools to support a variety of learning activities in an enquiry-based project. Teachers participated on a voluntary basis and were given limited compensation of the time they invested in the project. The teachers were coached by educational counsellors from an external organization. The educational counsellors helped the teachers reflect on their school's educational concept and their school's ambitions for intensifying its use of technology in line with this concept. Based on this reflection the learning arrangements were designed as the teachers saw best fit. This procedure was expected to promote the fit between the school's concept and the resulting use of technology. The teacher-as-designer approach, with an active, voluntary role for the participating teachers, was expected to favourably affect the implementation and integration of the designed learning arrangements by installing a sense of ownership in the teachers (Handelzalts 2009; Maher 1987). The researchers were not involved in the development of the learning arrangements.

\section{Participants and setting}

The five primary schools in this study were labeled as either 'traditional' (indicated as the Princess Amalia School and the Alma Mater School) or 'innovative' (indicated as the Beehive School, the Queen Beatrix School and the Beech Grove School). The labeling was based on interviews with stakeholders at each school at the start of the project. During the first year of the project the labeling of the schools was verified, based on teacher interviews and classroom observations. The teaching and learning practices at all participating schools met the quality standards of the Dutch Inspectorate of Education, as stated in the inspectorate's reports of the schools. At each school two or more teachers participated over a period of two school years. The grade levels of the participating classes varied from second to sixth grade.

In the 'traditional' schools educational goals were largely pursued through the use of teaching and learning materials with a more or less fixed content. Most instruction was given as direct whole-class instruction. After instruction, pupils mostly worked individually or in pairs on assignments or exercises directly linked to the textbook content and remedial instruction was given in smaller groups, informed by test results. The three 'innovative' schools in this study intended to make learning attractive and engaging for pupils, for instance by giving them more control over their learning process and by using inquiry learning activities. Science and social sciences were taught in multidisciplinary projects revolving around a certain theme. Subject matter was partly, in one school mainly, taught in the form of workshops. Classes were multi-aged, in order to give pupils the opportunity to learn with and from each other. Standard teaching and learning materials were mainly used as a general source of content and exercises at these schools. 


\section{Instruments and data collection}

For this multiple case study (Yin 2009) we operationalized technology integration both in quantitative and in qualitative terms. Combining a quantitative and a qualitative perspective on technology integration enabled theoretical triangulation of the collected data (Yin 2009). The quantitative character of the achieved technology integration (sub question 1) was captured through summarizing the number of different tools that were used in the learning arrangements, how many computers were available for the learning arrangements per class, how many learning arrangements were realized during the project and how many were abandoned before the end of the project. This information was based on data from embedded case studies (Yin 2009) of each learning arrangement. In these embedded cases studies we combined various methods of data collection that were all aimed at providing detailed information about how the technology use in the learning arrangements was carried out. These methods included: classroom observations (mostly videotaped), individual structured interviews with teachers, and logs and registration forms filled in by teachers and pupils during the realization of the learning arrangements. The exact methods (e.g. interview and observation protocols) varied, depending on the parameters of the learning arrangement under investigation. The combination of data collection methods enabled methodological triangulation (Yin 2009). The data were gathered by two teams of researchers from different research institutes, one team investigating one 'traditional' and one 'innovative' school, the other one 'traditional' and two 'innovative schools. The research teams were assigned to the schools at random. Both teams reported to each other regularly on decisions relating to each sub case study, thus clarifying the procedure they followed. This enabled us to audit the research procedures of the separate (sub) case studies (Halpern 1983). The descriptions of the learning arrangements based on the collected data were verified by the teachers involved.

For the qualitative character of the achieved technology integration (sub question 2) we looked at how the teachers themselves perceived and valued the developed technology use in their schools. This was determined through analysis of semi-structured focus group interviews that were held with the involved teams of teachers at each school, at the beginning of the first year (before the learning arrangements were realized, interview 1), at the end of the first year (one or two learning arrangements realized, interview 2), and at the end of the second year (all learning arrangements realized, interview 3). The focus group method was chosen because its dynamic enabled us to let the teachers e.g. corroborate, complement or challenge each other's accounts of the technology use and integration in their school, providing us with richer data than we would get from individual interviews (Williams and Katz 2001). The focus groups at each school consisted of two to eight teachers who participated in the development and/or the realization of one or more learning arrangements. As shown in Table 1 the composition of the focus groups varied somewhat across the study, as not all teachers were able to participate in each interview. For the second interview at the Alma Mater School only one teacher was available and the teachers at the Beech Grove School did not participate in the third round of interviews because the school left the project in the course of the second year (see also 3.3.3).

The interview protocol included topics concerning their participation in the project (e.g. 'what are your experiences with the project so far?'), the technology that was used, and the role it played in the school's classroom practice, (e.g. 'to what extent are teaching and learning supported by technology in your school?'). The question what differences can be found between the school types with regard to the quantitative and qualitative technology 
Table 1 Composition of focus groups per school and per interview

\begin{tabular}{llllll}
\hline & $\begin{array}{l}\text { Princess } \\
\text { Amalia School }\end{array}$ & $\begin{array}{l}\text { Alma Mater } \\
\text { School }\end{array}$ & $\begin{array}{l}\text { Beehive } \\
\text { School }\end{array}$ & $\begin{array}{l}\text { Queen Beatrix } \\
\text { School }\end{array}$ & $\begin{array}{l}\text { Beech Grove } \\
\text { School }\end{array}$ \\
\hline Interview 1 & $\mathrm{T} 1, \mathrm{~T} 2$ & $\mathrm{~T} 1, \mathrm{~T} 2, \mathrm{~T} 3$ & $\mathrm{~T} 1, \mathrm{~T} 2$ & $\mathrm{~T} 1, \mathrm{~T} 2, \mathrm{~T} 3, \mathrm{~T} 4, \mathrm{~T} 5$ & $\mathrm{~T} 1, \mathrm{~T} 2, \mathrm{~T} 3$ \\
Interview 2 & $\mathrm{T} 1, \mathrm{~T} 2$ & $\mathrm{~T} 2$ & $\mathrm{~T} 2, \mathrm{~T} 3$ & $\begin{array}{c}\text { T1, T2, T3, T4, T5, } \\
\mathrm{T} 6, \mathrm{~T} 7, \mathrm{~T} 8\end{array}$ & $\mathrm{~T} 2, \mathrm{~T} 4, \mathrm{~T} 5$ \\
Interview 3 & $\mathrm{T} 1, \mathrm{~T} 3, \mathrm{~T} 4$ & $\mathrm{~T} 2, \mathrm{~T} 4, \mathrm{~T} 5$ & $\mathrm{~T} 1, \mathrm{~T} 4, \mathrm{~T} 5$ & $\mathrm{~T} 1, \mathrm{~T} 9$ & - \\
\hline
\end{tabular}

integration (sub question 3) was answered based on the findings of the first two sub questions, as discussed in "This study" Sect.

\section{Analysis}

The focus group interviews were transcribed. These transcriptions and the descriptions of the learning arrangements were subjected to both quantitative and qualitative content analysis (Huberman and Miles 1994; Yin 2011). For the quantitative characterization of the technology integration we compared the quantitative data for the participating schools. In order to find indications of how the achieved integration of technology could be characterized qualitatively we first selected fragments within the transcripts and the descriptions that contained relevant information on the newly developed technology use. We selected the fragments based on the occurrence of one or more of the following topics:

1. The school's use of technology related to the developed learning arrangements.

2. The teachers' account of the role that the developed use of technology played in their classroom practice.

Within the selected fragments we then coded for the following two themes:

A. Descriptions and teachers' remarks with regard to the tools that were used.

B. Teachers' remarks on the perceived value of the newly introduced technology, in terms of the technology being perceived as an integral part of their classroom practice.

Within the fragments coded as theme A we then distinguished between the following labels:

a. tools-what was used (how many different tools per learning arrangement)

b. tools-how many computers were available for the learning arrangements

c. tools-how many technology-enhanced learning arrangements were realized and how many were abandoned during the project

These labels were used for the quantitative characterization of the technology integration. For theme B we used a grounded theory approach (Glaser and Strauss 1967; Strauss and Corbin 1998), as the existing literature on qualitative assessment of technology integration did not provide an analytical framework that fitted the basic assumptions behind the concept-guided approach. Through open coding we found types of teacher remarks that seemed to indicate that the technology was being perceived as an integral part of their classroom practice. With the quantitative characteristics of the technology use (theme A) and the most characteristic teacher remarks for theme B (perceived value of the developed technology use) we then looked for patterns in the data with regard to these themes. After addressing sub questions 1 and 2 by discussing the patterns that emerged 
from this analysis, sub question 3 was answered by comparing the patterns across the school types to look for differences that might be attributed to the different educational concepts.

\section{Results}

The quantitative character of the technology integration at all five schools is presented in Sect. Context of this study. The qualitative results for the teachers' perspective at the 'traditional' and the 'innovative' schools are discussed separately, in Sects. Participants and setting and Instruments and data collection respectively. Finally, we compare the patterns of the teachers' perspective between the school types (Sect. Analysis). Table 2 through Table 6 show what technology was used in each school, in the context of each learning arrangement. The activities or types of activities for which they were used are described in more detail in a previous study (de Koster et al. 2012).

At each school four learning arrangements were designed. The teachers at the 'traditional' schools developed relatively simple, transparent learning arrangements with one or two tools per arrangement and a varying intensity of technology use. At these schools all four learning arrangements were initially realized as planned. At the Princess Amalia School one learning arrangement was partly abandoned before the end of the project (the testing software in A1-1) and one was altered (the interactive use of the IWB in A1-2). The teachers' reflections on this are discussed in Participants and setting. The teachers at the three 'innovative' schools developed quite complex technology-supported learning arrangements, using a great variety of technology tools. The complexity of the learning arrangements presented the teachers at these schools with considerable logistical and technical challenges. At the Queen Beatrix School and the Beech Grove school this was one of the reasons why not all learning arrangements were realized. At the Beehive School all four learning arrangements were realized as planned, yet one was abandoned before the end of the project (B1-3).

\section{Quantities of tools}

No significant differences were found between the 'traditional' and the 'innovative' schools in terms of the total number of different tools that were used. In all five schools a

Table 2 Technology use in the learning arrangements at the Princess Amalia School

\begin{tabular}{lll}
\hline Code & Teacher & Description \\
\hline A1-1 & T1 & $\begin{array}{c}\text { Individual exercises and tests with mathematics exercise and test software, on desktop } \\
\text { computers in the classroom; grade } 5 \text { and } 6\end{array}$ \\
A1-2 & T2 & $\begin{array}{c}\text { Interactive classroom instruction on writing and spelling on IWB; some pupils are asked } \\
\text { to do an exercise on the IWB; grade } 3\end{array}$ \\
A1-3 & T3 & $\begin{array}{l}\text { Individual exercises and tests with reading comprehension exercise and test software on } \\
\text { laptop and desktop computers in the classroom; grade } 6\end{array}$ \\
A1-4 & T1 & $\begin{array}{c}\text { Assignments (on cards) in world orientation, involving web searching, processing and } \\
\text { presenting information, in pairs; grade } 3\end{array}$ \\
\hline
\end{tabular}


Table 3 Technology use in the learning arrangements at the Alma Mater School

\begin{tabular}{lll}
\hline Code & Teacher & Description \\
\hline A2-1 & T2 & $\begin{array}{c}\text { Assignments (on cards) in world orientation: gathering information from an online } \\
\text { database on desktop and laptop computers, use of digital photo cameras, individually or } \\
\text { in pairs; grade } 1 \text { and } 2\end{array}$ \\
A2-2 & T3 & $\begin{array}{c}\text { Mathematics classroom instruction about the metric system on the interactive whiteboard; } \\
\text { grade } 6\end{array}$ \\
A2-3 & T2, T4 & $\begin{array}{c}\text { Individual mathematics exercises with mathematics exercise software on desktop } \\
\text { computers; grade } 2\end{array}$ \\
A2-4 & T4 & $\begin{array}{c}\text { Reading' digital picture books, both with whole class (teacher-directed) and } \\
\text { independently in small groups and individually; Kindergarten (ages 4-5 years) }\end{array}$ \\
\hline
\end{tabular}

combination of desktop and/or laptop computers and IWBs was used in most learning arrangements. By the end of the project the IWB had replaced the traditional chalkboard in the participating classes in all five schools. In addition to these tools the 'traditional' schools used exercise and/or testing software in two out of four learning arrangements. Both 'traditional' schools used a total of seven tools (hardware and software) across the learning arrangements. At the 'innovative' schools the use of computers and the IWB was combined with the use of audiovisual tools and digital microscopes. At two of these schools a total of eight different tools was used, while at one school six different tools were used. However, when we look at the number of tools that were used within one learning arrangement, we find that at the 'traditional' schools only one to three different tools were used per learning arrangement (as can be seen in Tables 2, 3), while at the 'innovative' schools most learning arrangements were supported by three or more tools (Tables 4, 5, 6). The numbers of computers per class (desktop and laptop) did differ between the schools, but not between the school types, as shown in Table 7 .

In three schools (one 'traditional' and two 'innovative') there were four desktop computers per classroom and at one of the 'innovative' schools there were also six shared desktop computers. In one 'traditional' school there were two desktop computers per classroom, and in one 'innovative' school most classes had none. These schools on the other hand had the highest number of laptops per class. The laptops were shared among a

Table 4 Technology use in the learning arrangements at the Beehive School

\begin{tabular}{|c|c|c|}
\hline Code & Teacher & Description \\
\hline B1-1 & $\mathrm{T} 2$ & $\begin{array}{l}\text { Pupils use digital cameras to make pictures and video clips around a theme, make } \\
\text { presentations with their pictures, their video clips and information from the web, and } \\
\text { give presentations on the IWB; grades } 2 \text { through } 4\end{array}$ \\
\hline B1-2 & $\mathrm{T} 1$ & $\begin{array}{l}\text { Pairs of pupils perform a chemical experiment and record and edit a video of the } \\
\text { experiment, and show videos on the IWB to the class; grades } 4 \text { through } 6\end{array}$ \\
\hline B1-3 & $\mathrm{T} 2, \mathrm{~T} 3$ & $\begin{array}{l}\text { Pupils (individual, pairs, small groups) practise multiplication tables through non-digital } \\
\text { games connected with multiple intelligences, available in database on school's digital } \\
\text { network; grades } 3 \text { through } 6\end{array}$ \\
\hline B1-4 & $\mathrm{T} 4$ & $\begin{array}{l}\text { Pupils (pairs, small groups) photograph groups of objects with digital photo cameras. } \\
\text { Teacher prints photographs and pupils use photographs to make multiplication } \\
\text { booklets; grade } 2\end{array}$ \\
\hline
\end{tabular}


Table 5 Technology use in the learning arrangements at the Queen Beatrix School

\section{Code Teacher Description}

B2-1 T2, T5 Pupils (individual, pairs, small groups) report on current events using a variety of tools like digital cameras, pod recorders and presentation software; grades 4/5/6

B2-2 T4 Teachers give a workshop on the use of several tools. Pupils (individually or in pairs) formulate a research question related to the theme 'our house', carry out a small research project using a variety of tools (internet, digital microscope) and present their results to the class on IWB or on wall posters; grades 4 through 6

B2-3 T1, T9 Teachers give a workshop on web searching. Pupils (individually or in pairs) formulate a research question related to the theme 'the Caribbean' and carry out a small research project, mainly on the web, and present their results to the class on IWB or on wall posters; grades $4 / 5 / 6$

Table 6 Technology use in the learning arrangements at the Beech Grove School

\begin{tabular}{lll}
\hline Code & Teacher & Description \\
\hline B3-1 & T1 & $\begin{array}{l}\text { Pupils (individually or in pairs) formulate a research question on a social science subject } \\
\text { and carry out a small research project using a variety of tools, like the internet, digital } \\
\text { microscopes and topographical software; grades } 1 / 2 / 3\end{array}$ \\
B3-2 & T2, T3 & $\begin{array}{l}\text { Teachers give a workshop on multiple intelligences and give pro-active guidance on the } \\
\text { use of connected to multiple intelligences while pupils (individually or in pairs) } \\
\text { formulate a research question on a subject of their choice and carry out a small research } \\
\text { project with the use of the internet, digital microscopes, topographical software, laptop } \\
\text { computers and the IWB; grades } 1 / 2 / 3\end{array}$ \\
\hline
\end{tabular}

number of classes in four out of five schools. So apart from the number of different tools per learning arrangement no clear distinctions could be found between the school types in quantitative terms.

\section{Integration of technology at the 'traditional' schools: the teachers' perspective}

\section{Princess Amalia School}

According to the teachers at the Princess Amalia School the laptop computers soon became integrated into classroom practice of the participating classes during the first project year. The exercise software for mathematics (A1-1) and the exercise and test software for reading comprehension (A1-3) were also soon used routinely in all upper grades.

Int. 2 T1: It has become a logical whole. It soon became something logical. [...] It became a self-evident use.

In general the convenience of the increased possibilities of the textbook-supporting software was mentioned as an important aspect several times by the teachers. 
Table 7 Number of computers per class per school

\begin{tabular}{|c|c|c|c|c|c|c|}
\hline School & $\begin{array}{l}\text { \# Desktop } \\
\text { computers } \\
\text { per class }\end{array}$ & $\begin{array}{l}\text { \# Desktop } \\
\text { computers } \\
\text { shared }\end{array}$ & $\begin{array}{l}\text { \# Laptop } \\
\text { computers } \\
\text { per class }\end{array}$ & $\begin{array}{l}\text { \# Laptop } \\
\text { computers } \\
\text { shared }\end{array}$ & $\begin{array}{l}\text { \# Classes } \\
\text { sharing } \\
\text { computers }\end{array}$ & $\begin{array}{l}\text { Av. \# } \\
\text { computers } \\
\text { per class }\end{array}$ \\
\hline \multicolumn{7}{|l|}{ 'Traditional' } \\
\hline Princess Amalia School & 4 & & & 8 & 3 & 6.7 \\
\hline Alma Mater School & 2 & & & 35 & 4 & 10.7 \\
\hline \multicolumn{7}{|l|}{ 'Innovative' } \\
\hline Beehive School & & & 10 & & & 10 \\
\hline Queen Beatrix School & 4 & 6 & & 10 & 5 & 7.2 \\
\hline Beech Grove School & 4 & & & 9 & 3 & 7 \\
\hline
\end{tabular}

a Average number of computers per class, both desktop and laptop, based on number of computers and number of classes sharing computers

Int. 3 T3: I've mainly been doing the comprehensive reading [software]. That was just positive. That's just going well. And yeah, it didn't give me a lot of extra work, it feels like.

T1: Yes, I'm really happy with comprehensive reading on the computer too. I think that's a real enrichment. Especially those [assignment] cards.

The mathematics testing software however (A1-1) was perceived as poorly usable and was therefore abandoned. During the implementation of the fourth learning arrangement (A14), the use of the available computers was intensified because of the focus on student use of the internet and presentation software in this learning arrangement. This may explain why by the end of the project the number of available computers was perceived by the teachers as insufficient even though at the end of the first year they had perceived the number of computers to be sufficient.

Int. 3 T2: [...] we still don't have enough computers. [...] They need a lot of computers to search for information, to type in Word, to make a Powerpoint slideshow.

T4: So, yeah, for science and social science you couldn't really do without.

T2: You really can't.

The teachers seemed to unanimously perceive a wide availability of computers as indispensable for their classroom practice. The fact that by the end of the project the IWB had completely replaced the blackboard in the school shows that this tool was integrated as well. Nevertheless few explicitly positive comments about the IWB were made by the teachers during the focus group interviews. By the end of the project the board was still used in language lessons (A1-2), but in a less interactive way.

Int. 3 T1: At the start when I did that learning arrangement with spelling I made my own lessons [for the IWB]. But when can you do that? [...] You scan your lesson and you do something with the board. But not all that's possible.

Int: And that's a matter of time?

T1: Yes. We have very little time. 


\section{Alma Mater School}

The first learning arrangement at this school (A2-1) contained only a limited amount of technology use, restricted to laptops (e.g. for searching information in an information database) and infrequent use of the digital camera. This was due to the limited use of technology that was prescribed by the learning materials for this learning arrangement (i.e. the assignment cards, see Table 3). Also in the third learning arrangement (A2-3) technology use was limited. Here the software exercises from the math program replaced only the complementary (program-independent) online exercises that the pupils did previously. The teacher did not make use of the available options for differentiation in the software, because of the limited time for getting acquainted with the software and limited technical support. The IWB on the other hand was used regularly, replacing the chalkboard completely. The teachers gave several examples of ways in which the IWB was used ad hoc during instruction lessons to support the introduction of new concepts.

Int. 1 T3: Almost every day there is something of which we all say: 'how exactly does that work?' and we want to know more about it and you can show it right away [using the internet and IWB].

Int. 2 T2: [The IWB] is simply being used in the school. Yes. Daily. It is just in replacement of the chalkboard. It's not like: right, now we're going to do something with the IWB. That's not what it's like.

Grades 1 and 2 (combined in one class) received an additional fifteen laptops. By the end of the first year of the project, the teacher of this class indicated a strong increase in the computer use by her pupils, mainly on four laptops that were constantly available for the pupils in her classroom, ready to use. She was very enthusiastic about the increased possibilities for the students on the laptops.

Int. 2 T2: Back then 5 min just wasn't enough. You'd have to find a laptop, that was working, or didn't have an empty battery. [...] And now we have it all ready at hand. And therefore they're working on the laptops a lot more. And therefore they can do a lot more with them. I can use every 5 min. If they have nothing else to do, they can just sit down and do math or language or figure out something to do.

At this school as well, the teachers were very positive about the conveniences of the software that was linked to the learning materials that were used. The software to a large extent replaces the paper materials that were used before.

Int. 2 T2: Now I've got it all digitally. [...] Before, I'd look up in the [teacher's] manual what I'd have to do. But now it has everything, per day [it says] what we have to do that day. Also the worksheets, you know, the examples. Yes, everything is in it.

\section{Integration of technology at the 'innovative' schools - the teachers' perspective}

\section{Beehive School}

The first two learning arrangements at the Beehive School included the use of the IWB, both by the teachers and the pupils. The teachers initially also gave examples of using the IWB for activities outside the learning arrangements. 
Int. 2 T3: I wouldn't want to miss [the IWB] anymore.

T2: It's ideal. For example after the school holidays: 'Where have you been on vacation?'. And then you google and search and you can fly across those mountains and 'wow, here's a lake' and yes, that's really cool. And educating.

Remarkably however, by the end of the second project year, the interviewed teachers at the Beehive School indicated that their appreciation and use of the IWB gradually decreased, although they did not abandon its use altogether. The laptop computers turned out to be more important to their teaching and learning than the IWB.

Int. 3 T4: We don't have an IWB. But we will get one. Although we didn't really miss it that much this year. Because if we wanted to do something we'd ask if we could use your board or something.

T1: For me that's not the first thing that I would miss if it wasn't there either. I think it's very useful, I do see its added value, but actually I find the laptops far more important than the IWB.

In general the technology was perceived as obvious and indispensable. The tools had become 'one of the materials'.

Int. 2 T2: I wouldn't say it has become second nature to us, but it has become a normal learning material, just like the books you use, or whatever. Material. It's just one of the materials. [Before] I would really have to think 'how can I use film or visual material, or sound on MP3 players?'. I would really have to think hard to come up with something. From nothing, like. Yeah, and now I feel that I have a foundation on which I can build.

Int. 3 T1: I couldn't do without anymore. [...]

T4: I agree.

T1: But I also think it's important for [the pupils] to use other sources as well.

With this and other remarks the teachers stressed that they find the use of technology in the classroom very important, while at the same time indicating that this importance is relative and analogue materials should be used as well, i.e. technology should be complementary to the traditional materials.

\section{Queen Beatrix School}

After designing the learning arrangements the teachers at the Queen Beatrix School initially expressed some fears of not being able to embed the new technology use in their everyday practice.

Int. 1 T1: [...] When we started this project we had [the idea] that we could use the new tools in our classrooms and now it has come down to two separate workshops [outside of the classrooms]. Those are really cool and our ideas are in them but we haven't discussed what we can do with [the tools] in our classrooms.

T3: A workshop is great but it's something extra.

T1: It's not your foundation.

After the first project year however, they made many remarks indicating their perception of the new tools as obvious and indispensable, both in the workshops and in the classroom. 
Int. 2 T4: And now I can hardly imagine what we'd do without the cameras. [...] [the computer] is on... T2: Yeah, that thing is on $24 / 7$ almost.

Int. 3 T1: Yes, really a lot. A lot of things that you're not really aware of. [...] It's automatic, and then afterwards you [T9] say: but you also did this and that...

By the end of the third and final learning arrangement the time investment in the project did not feel like something extra anymore. It had fully replaced the way these projects had been carried out before the start of the project, when much less technology was used.

Int. 3 T9: [At the beginning of the project] there was simply not enough time. The children would come up to you and say: how does this [tool] work, how does that work? And if you as a teacher didn't know then we just wouldn't do it. [...]

T1: Yeah, and also because it was something extra, like. Last year. Then that takes an effort in itself. And then in addition you'd have to figure out stuff, that turns out to be quite complicated. And this year it's just a lot better, because it's not something extra but it's deepening something that you were already doing.

The IWB was used daily for presentations by pupils and for drawing mind maps, in addition to the planned and/or ad hoc illustration of topics during whole-class instruction by using the internet.

Int. 2 T6: $[\ldots]$ this afternoon we were doing experiments about fireworks and how it is made. Normally you'd search and fiddle for a long time and now you have a student look up the [recent] fireworks disaster on the computer. Before,... well, you could order a video tape and it would take 6 weeks and it wouldn't be meaningful for the kids. Now it's very easy to ad hoc react to stuff that's important for students. I find that a great advantage of this board.

Int. 3 T9: the other day we read a story about forest fires in comprehensive reading. Then you can immediately switch to the news, because there were forest fires in Australia. Then you can show yesterday's news bulletin.

\section{Beech Grove school}

The technology use that was developed at the Beech Grove School was highly appreciated by the teachers. Several comments were made on the value of the IWB and the computers.

Int. 1 T1: At one point, just from the top of my head, I gave a lesson about the antiquity. [...] Just looked [it] up and talked about it. [...] I asked: what do you know about this? And a lot of stories came out. That's just so meaningful. You just don't get that in an ordinary history lesson.

Int. 2 T5: We had only two [computers] or so. [...] So you'd have to make the decision for yourself all the time: which child needs it the most at this moment? And that's really hard. Because one uses it for spelling, the other for his research questions. And they all need it badly. So this is great, that it's possible.

T2: At some point [the counsellor supporting the teachers] mentioned how much she enjoyed constantly seeing children working on the computers. Instead of being allowed a certain amount of time. They're always in use.

The teachers also gave many examples of activities that have been made possible or a lot easier and more accessible by the use of technology, like writing on the computer instead of on paper, indicating that the technological tools are to an extent replacing the traditional means rather than complementing them. 
Int. 2 T5: If you just look at the children that have difficulties writing. And write much longer texts on the computer than if they had to do it by hand. Or that they can add an image, which makes it fun of course. While before... [...] There's so much more in it than in [the textbooks].

\section{Similarities and differences between the school types}

In this section we summarize the similarities and differences that were found in the quantitative and the qualitative characteristics of the technology integration. With regard to the quantitative characterization we found that at the 'traditional' schools only one to three different tools were used per learning arrangement, while at the 'innovative' schools most learning arrangements were supported by three or more tools. Apart from the number of different tools per learning arrangement no clear distinctions were found between the school types in quantitative terms. With regard to the qualitative characteristics we found the following types of remarks that seemed to indicate that the technology was perceived as an integral part of the teachers' practice: technology perceived as common, matter-offactly; technology perceived as indispensable; technology perceived as either replacing or complementing the traditional tools. The following comparison between the school types was based on these characteristics of the teachers' remarks. The quotes that are used to illustrate these similarities and differences are taken from the quotes presented in Participants and setting and Instruments and data collection.

\section{Technology perceived as common}

At all five schools teachers' comments showed they perceived most of their new technology use as common or obvious. This is reflected in phrases like 'You're not aware of that anymore because it's so easy' (Princess Amalia School, T4), '[The IWB] is simply being used' (Alma Mater School, T2), 'It's just one of the materials' (Beehive School, T2), and 'A lot of things that you're not aware of, it's automatic' (Queen Beatrix School, T1).

\section{Technology perceived as indispensable}

Similarly, at all five schools the teachers expressed perceiving their new technology use as indispensable, as reflected in phrases like 'You couldn't really do without' (Princess Amalia School, T4), 'I couldn't do without anymore' (Beehive School, T1), 'I can hardly imagine what we'd do without the cameras' (Queen Beatrix School, T4), and '[the pupils] all need it badly' (Beech Grove School, T5). At one 'traditional' school one tool (math software) was abandoned because it did not function as expected. At one 'innovative' school on the other hand, one learning arrangement was 'suspended' because the ELE for which it was designed wasn't realized yet, which may have indicated implicitly that the ELE was perceived as indispensible even before it existed.

\section{Technology perceived as replacing and/or complementary}

With regard to the technology being perceived by the teachers as replacing and/or complementing the materials that were used previously a slightly more varied picture was found. In all five schools by the end of the project the IWB had replaced the traditional chalkboard. It was highly valued for its multimodal possibilities, and especially the added 
value of visualizing lesson content on the IWB was mentioned frequently by teachers from both school types. The software used by the 'traditional' schools did both complement and replace the traditional materials, as computer exercises were combined with paper exercises and some paper tests were replaced completely by digital tests. At one of the 'innovative' schools the teachers agreed that the value of the technological tools is relative, as 'it's important for [the pupils] to use other sources as well' (Beehive School, T1). At the other 'innovative' schools the enthusiasm about the value of technology seemed less conditional. At the end of the project the teachers at one of these schools agreed that the new use of technology was 'not something extra' anymore (Queen Beatrix School, T1) and at the other school the added possibilities of the tools were stressed, comparing 'before' (i.e. working on paper and in textbooks) with 'now' (working on the computer).

\section{Conclusion and discussion}

In this study five schools with either a 'traditional' or an 'innovative' school concept were studied as they participated in a two-year project of concept-guided development of instructional use of technology. We explored how the achieved integration of technology in two 'traditional' and three 'innovative' elementary schools that developed their use of technology in a concept-guided way could be characterized in quantitative and qualitative terms. We studied the technology-rich learning arrangements that were developed in this project (embedded case studies, quantitative and qualitative measurements) and how the teachers perceived their newly developed technology use (focus group interviews), and we compared the emerging patterns between the school types.

\section{Quantitative character of technology integration compared}

The quantitative character of the integrated technology was measured through summarizing the number of different tools that were used in the learning arrangements and how many computers were available per class. When looking at the number of different tools that were used we found that the 'traditional' schools tended to use less tools per learning arrangement than the 'innovative' schools. The numbers of computers per class (desktop and laptop) did differ between the schools, but not between the school types. Three schools (one 'traditional' and two 'innovative' schools) had an average of around seven computers per class, while at one 'traditional' and one 'innovative' school each class had around ten computers at its disposal. In one 'traditional' school one learning arrangement was partly abandoned before the end of the project and one was continued in a 'toned-down' fashion. At one 'innovative' school one learning arrangement was abandoned (suspended) before the end of the project.

\section{Qualitative characterization compared}

The qualitative character of the integrated technology was measured through the value of the technology as perceived by the teachers. With respect to the labels 'technology perceived as common' and 'technology perceived as indispensable' no differences were found between the school types. At all five schools the technology that was used in the learning arrangements that were continued was in general perceived as common or 'automatic' and most of it also as indispensable. Both with regard to specific tools, like the IWB, and to technology in general teachers from both school types expressed that they 'could not do 
without' anymore, indicating that at least some of the tools and their applications were highly valued by these teachers. In all five schools some of the newly introduced technology replaced the non-digital materials while other tools merely complemented the existing materials or tools. All schools replaced the chalkboard with IWBs in all participating classes. The software used by the 'traditional' schools did both complement and replace the traditional materials. At the 'innovative' schools a slight within-group difference was seen between the schools. At one school the value of the new tools was explicitly put into perspective, the IWB being considered less important than the laptops and more stress being put on the complementary value of technology, while at the other two schools the tools seemed to be valued more unconditionally and more stress was put on technology replacing 'the old'.

\section{Discussion of implications}

Our findings from this explorative case study suggest that a concept-guided development of technology use does promote the integration of the technology use that supports different pedagogies when defining technology integration in a qualitative way. This supports earlier findings that minimizing the distance between technology innovation and the school's educational practice promotes technology integration (Zhao et al. 2002). We also conclude that when we define the integration of technology in a way that encompasses the teachers' appreciation of the technology, the achieved integration at schools with different school concepts does not necessarily differ. This stands in contrast to the suggestion that the highest stage of technology integration is only found in a context of innovative, constructivist teaching and learning (Sandholtz et al. 1997; Mueller et al. 2008).

The data also suggest that what exactly is valued in the tools and applications that are used quite surprisingly does not vary greatly among the schools. Especially with regard to the IWB the teachers' responses seemed to indicate that the multimodality of this tool and its possibilities for visualizing subject matter is valued equally in both school types. On the other hand, the interactive possibilities of the tool in terms of giving pupils more control over what happens on the board were not mentioned at any of the schools in the focus group interviews, even though in both school types we did observe this type of interactivity taking place (Authors 2013). It remains unclear whether the teachers did not value this affordance of the IWB as much as is generally assumed, or that they were not aware of their appreciation because they were taking it for granted already. Similarly, the fact that the teachers at one of the 'innovative' schools by the end of the project realized they valued the laptop computers more than the IWB might be seen as a failed integration of the IWB. On the other hand it may also indicate a gradually increasing articulation of the teachers' ideas about their needs with regard to the use of technology. Taking the affordances of technology for granted and developing more articulated ideas about technology in the classroom might be seen as additional signs that technology is becoming integrated in the teachers' thinking and practice and thus need to be added to out conceptual framework for technology integration. These findings underscore the importance of including the teachers' perception of their technology use in our definition of technology integration and of understanding it as a factor to be reckoned with when supporting a school in developing its technology use.

\section{Discussion of limitations and future research}

To what extent the found level of integration can be attributed to the concept-guided approach cannot be concluded from this exploratory study. More research in schools with a 
wider range of educational concepts is needed to investigate how and under which conditions concept-guided development of technology use promotes technology integration. Other factors are likely to have contributed to the achieved level of integration as well, like the teachers' views and beliefs about technology at the outset of the project, their general attitude toward innovation, how they were prepared for the integration of the developed technology use, possible tensions within the teams of teachers-as-designers, the role of the counselors and school leaders and the support and resources that were provided. Further research is needed to gain more insight into these factors in the context of a concept-guided approach. Finally, in this study we focused on the extent to which the teachers involved in this project succeeded in integrating technology into their classroom practices. The quality and outcomes of the teaching and learning, both before and after the integration of technology, were beyond the scope of this study, but obviously deserve equal attention. Further studies will therefore also have to focus on the extent to which the integrated technology use actually helps to improve these practices.

Funding This study was funded by Kennisnet.

\section{Compliance with ethical standards}

Conflict of interest The authors declare that they have no conflict of interest.

Open Access This article is distributed under the terms of the Creative Commons Attribution 4.0 International License (http://creativecommons.org/licenses/by/4.0/), which permits unrestricted use, distribution, and reproduction in any medium, provided you give appropriate credit to the original author(s) and the source, provide a link to the Creative Commons license, and indicate if changes were made.

\section{References}

Archer, K., Savage, R., Sanghera-Sidhu, S., Wood, E., Gottardo, A., \& Chen, V. (2014). Examining the effectiveness of technology use in classrooms: A tertiary meta-analysis. Computers \& Education, 78, $140-149$.

de Koster, S., Kuiper, E., \& Volman, M. (2012). Concept-guided development of ICT use in 'traditional' and 'innovative' primary schools: what types of ICT use do schools develop? Journal of Computer Assisted Learning, 28(5), 454-464.

de Koster, S., Volman, M., \& Kuiper, E. (2013). Interactivity with the interactive whiteboard in traditional and innovative primary schools: An exploratory study. Australasian Journal of Educational Technology. doi:10.14742/ajet.291.

Cheung, A. C. K., \& Slavin, R. E. (2012). How features of educational technology applications affect student reading outcomes: A meta-analysis. Educational Research Review, 7(3), 198-215.

Cheung, A. C. K., \& Slavin, R. E. (2013). The effectiveness of educational technology applications for enhancing mathematics achievement in K-12 classrooms: A meta-analysis. Educational Research Review, 9, 88-113.

de Kock, A., Sleegers, P., \& Voeten, M. J. M. (2005). New learning and choices of secondary school teachers when arranging learning environments. Teaching and Teacher Education, 21, 799-816.

Ertmer, P. A., \& Ottenbreit-Leftwich, A. (2013). Removing obstacles to the pedagogical changes required by Jonassen's vision of authentic technology-enabled learning. Computers \& Education, 64, 175-182. doi:10.1016/j.compedu.2012.10.008.

Glaser, B. G., \& Strauss, A. (1967). The discovery of grounded theory: Strategies for qualitative research. New York: Aldine.

Halpern, E. S. (1983). Auditing naturalistic inquiries: the development and application of a model. Indiana: Unpublished doctoral dissertation.

Handelzalts, A. (2009). Collaborative curriculum development in teacher design teams. Doctoral dissertation, University of Twente. 
Hew, K. F., \& Brush, T. (2007). Integrating technology into K-12 teaching and learning: Current knowledge gaps and recommendations for future research. Educational Technology Research and Development, $55,223-252$.

Huberman, A. M., \& Miles, M. B. (1994). Data management and analysis methods. In N. K. Denzin \& Y. S. Lincoln (Eds.), Handbook of qualitative research (pp. 432-435). Thousand Oaks: Sage Publications.

Inan, F. A., \& Lowther, D. L. (2010). Factors affecting technology integration in K-12 classrooms: A path model. Educational Technology Research and Development, 58(2), 137-154.

ISTE. (2002). National Education Technology Standards for Students. Eugene: ISTE.

Kampylis, P., Law, N., Punie, Y., Bocconi, S., Brecko, B., Han, S., et al. (2013). ICT-enabled innovation for learning in Europe and Asia: Exploring conditions for sustainability, scalability and impact at system level. Luxembourg: Publications Office of the European Union. doi:10.2791/2530.

Lemke, C., Coughlin, E., \& Reifsneider, D. (2009). Technology in schools. What the research says: An update. Culver City: Commissioned by Cisco.

Lewin, C., \& McNicol, S. (2015). Creating the future classroom: Evidence from the iTEC project. Brussels: Future Classroom Lab.

Lim, C. P. (2007). Effective integration of ICT in Singapore schools: Pedagogical and policy implications. Educational Technology Research and Development, 55(1), 83-116.

Maher, C. A. (1987). The teacher as designer, implementer, and evaluator of children's mathematical learning environments. Journal of Mathematical Behavior, 6(3), 295-303.

Mandell, S., Sorge, D. H., \& Russell, J. D. (2002). TIPs for technology integration. TechTrends, 46(5), 39-46.

Mor, Y., \& Mogilevsky, O. (2013). The learning design studio: Collaborative design inquiry as teachers' professional development. Research in Learning Technology, 21, 22054. doi:10.3402/rlt.v21i0.2205.

Mueller, J., Wood, E., Willoughby, T., Ross, C., \& Specht, J. (2008). Identifying discriminating variables between teachers who fully integrate computers and teachers with limited integration. Computers \& Education, 51, 1523-1537.

Niederhauser, D. S., \& Stoddart, T. (2001). Teachers' instructional perspectives and use of educational software. Teaching and Teacher Education, 17(1), 15-31. doi:10.1016/S0742-051X(00)00036-6.

OECD. (2015). Students, computers and learning: Making the connection. Paris: PISA, OECD Publishing. doi:10.1787/9789264239555-en.

Pelgrum, W. J. (2001). Obstacles to the integration of ICT in education: Results from a worldwide educational assessment. Computers \& Education, 37, 163-178.

Sandholtz, J. H., Ringstaff, C., \& Dwyer, D. C. (1997). Teaching with technology: Creating studentcentered classrooms. New York: Teachers College Press.

Strauss, A., \& Corbin, J. (1998). Basics of qualitative research: Techniques and procedures for developing grounded theory (2nd ed.). Thousand Oaks: Sage.

Tolmie, A. (2001). Examining learning in relation to the contexts of use of ICT. Journal of Computer Assisted Learning, 17, 235-241. doi:10.1046/j.0266-4909.2001.00178.x.

Tondeur, J., Hermans, R., van Braak, J., \& Valcke, M. (2008). Exploring the link between teachers' educational belief profiles and different types of computer use in the classroom. Computers in Human Behavior, 24, 2541-2553.

Van Braak, J., Tondeur, J., \& Valcke, M. (2004). Explaining different types of computer use among primary school teachers. European Journal of Psychology of Education, 19(4), 407-422.

Vanderlinde, R. (2011). School-based ICT policy planning in a context of curriculum reform. Gent: Universiteit Gent.

Vanderlinde, R., \& van Braak, J. (2010). Implementing an ICT curriculum in a decentralised policy context: Description of ICT practices in three Flemish primary schools. British Journal of Educational Technology, 41(6), E139-E141. doi:10.1111/j.1467-8535.2010.01111.x.

Vanderlinde, R., van Braak, J., \& Hermans, R. (2009). Educational technology on a turning point: Curriculum implementation in Flanders and challenges for schools. Educational Technology Research and Development, 57, 573-584.

Wang, Q. (2008). A generic model for guiding the integration of ICT into teaching and learning. Innovations in Education and Teaching International, 45(4), 411-419.

Ward, L., \& Parr, J. M. (2010). Revisiting and reframing use: Implications for the integration of ICT. Computers \& Education, 54(1), 113-122.

Williams, A., \& Katz, L. (2001). The use of focus group methodology in education: Some theoretical and practical considerations. International Electronic Journal for Leadership in Learning, 5(3).

Yin, R. K. (2009). Case study research. Design and methods. Thousand Oaks: Sage.

Yin, R. K. (2011). Qualitative research from start to finish. New York: Guilford Press. 
Zhao, Y., Pugh, K., Sheldon, S., \& Byers, J. L. (2002). Conditions for classroom technology innovations. Teachers College Record, 104(3), 482-515.

Sandra de Koster completed her B.Sc. Educational Sciences at the University of Amsterdam and her M.Sc. Educational Sciences at VU University (cum laude). She currently works as a thesis supervisor in The Netherlands. Her research interests include professional development, teacher beliefs, concept-guided development of technology use and technology integration.

Monique Volman is a full professor of Education and director of the 'Education' program at the Research Institute of Child Development and Education of the University of Amsterdam. Main areas in her research are learning environments for meaningful learning, diversity and the use of ICT in education.

Els Kuiper is a researcher at the Kohnstamm Institute for educational research in Amsterdam and a lecturer at the College and Graduate School of Child Development and Education of the University of Amsterdam. Her main research interests are the use of technology in education and the effects of social diversity on learning processes and outcomes. 